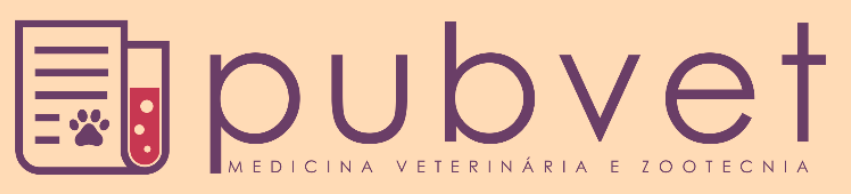

https://doi.org/10.31533/pubvet.v12n12a225.1-13

\title{
Estratégias para antecipação da puberdade em novilhas Bos taurus indicus pré-púberes
}

\author{
Felipe Martins Batista Silva ${ }^{\ominus}$, Dyomar Toledo Lopes $^{2 *} \bullet$, Henrique Trevizoli Ferraz ${ }^{3}$, \\ Marco Antônio de Oliveira Viu ${ }^{3} \bullet$, Dirceu Guilherme de Souza $\operatorname{Ramos}^{3} \bullet$, Klaus Casaro \\ Saturnino $^{3}$, Cássio Aparecido Pereira Fontana ${ }^{3}$, Jucielly Machado Amado Silva ${ }^{1}$, \\ Flavia Viana Leso ${ }^{10}$
}

${ }^{1}$ Discente do curso de Medicina Veterinária da Universidade Federal de Goiás - Regional Jataí, Goiás, Brasil. 2Professor do curso de Medicina Veterinária da Universidade Federal de Goiás - Regional Jataí, Goiás, Brasil. ${ }^{3}$ Professor Doutor do curso de Medicina Veterinária da Universidade Federal de Goiás - Regional Jataí, Goiás, Brasil. *Autor para correspondência, E-mail: $\underline{\text { dtl.ufg@gmail.com }}$

RESUMO. A bovinocultura brasileira é uma das maiores potências mundiais na produção de proteína animal, porém é uma produção caracterizada por baixa eficiência quando comparada a países de primeiro mundo. O rebanho nacional é predominantemente Bos taurus indicus, sendo que a maioria dos animais apresentam baixa resposta reprodutiva devido à sazonalidade das forragens, o inadequado manejo das pastagens e inexistência de suplementação no período de crescimento. Novas biotecnologias reprodutivas têm surgido nas últimas décadas e algumas melhoras nos índices reprodutivos aconteceram. Porém, a precocidade sexual das novilhas continua deixando a desejar, pois a maioria torna-se púbere em idade maior do que seria o ideal do ponto de vista econômico, resultando em idade ao primeiro parto avançada, menor produção de bezerros durante a vida produtiva útil, menor quantidade de fêmeas para reposição, etc. Para tentar solucionar esse problema, pesquisadores têm estudado os fatores que influenciam a manifestação da puberdade nessas fêmeas bem como estratégias para a antecipação da puberdade, o que permite aumento da eficiência reprodutiva com o maior número de bezerros produzidos por fêmea durante sua vida útil. Objetivou-se, com esse este trabalho, revisar a literatura acerca do mecanismo fisiológico de estabelecimento da puberdade, dos fatores que a influenciam, além de abordar estratégias para antecipá-la.

Palavras chave: eficiência reprodutiva, fêmeas bovinas, indução da puberdade, precocidade sexual

\section{Puberty anticipation strategies in pre-pubescent heifers Bos taurus indicus}

\begin{abstract}
Brazilian cattle breeding is one of the largest world powers in the production of animal protein, but it is a production characterized by low efficiency when compared to first world countries. The national herd is predominantly Bos taurus indicus, with most of the animals presenting low reproductive response due to the seasonality of the forages, the inadequate pasture management and the absence of supplementation during the growth period. New reproductive biotechnologies have emerged in recent decades and some improvements in reproductive rates have taken place. However, the sexual precocity of heifers continues to be lacking, since most become pubescent at an age greater than would be ideal from the economic point of view, resulting in advanced age at first calving, lower calf production during useful productive life, fewer females for replacement, etc. In order to solve this problem, researchers have studied the factors that influence the manifestation of puberty in these females as well as strategies for the anticipation of this event, which
\end{abstract}


allows an increase in reproductive efficiency with the highest number of calves produced by females during their life. The objective with this study was to review the literature on the physiological mechanism of establishment of puberty, the factors that influence it, and to approach strategies to anticipate it.

Keywords: reproductive efficiency, bovine females, puberty induction, sexual precocity

\title{
Estrategias para la anticipación de la pubertad en novillas prepúberes Bos taurus indicus
}

\begin{abstract}
RESUMEN. La ganadería brasileña es una de las mayores potencias mundiales en la producción de proteína animal, sin embargo, es una producción caracterizada por baja eficiencia cuando se compara con los países de primer mundo. El rebaño nacional es predominantemente Bos taurus indicus, siendo que la mayoría de los animales presentan baja respuesta reproductiva debido a la estacionalidad de los forrajes, el inadecuado manejo de los pastos y la inexistencia de suplementación en el período de crecimiento. Nuevas biotecnologías reproductivas han surgido en las últimas décadas y algunas mejoras en los índices reproductivos han ocurrido. Sin embargo, la precocidad sexual de las novillas sigue dejando a desear, pues la mayoría se vuelven púberes en edad mayor de lo que sería el ideal desde el punto de vista económico, resultando en edad avanzada al primer parto, menor producción de terneros durante la vida productiva útil, menor cantidad de hembras para reposición, etc. Para tratar de solucionar este problema, los investigadores han estudiado los factores que influencian la manifestación de la pubertad en estas hembras, así como estrategias para la anticipación de la pubertad, lo que permite un aumento de la eficiencia reproductiva con el mayor número de terneros producidos por hembra durante su vida útil. Se objetivó, con este trabajo, revisar la literatura acerca del mecanismo fisiológico de establecimiento de la pubertad, de los factores que la influencian, además de abordar estrategias para anticiparla.
\end{abstract}

Palabras clave: eficiencia reproductiva, hembras bovinas, inducción de pubertad, precocidad sexual

\section{Introdução}

A pecuária brasileira é conhecida mundialmente pelo seu elevado potencial produtivo de carne, contendo o maior rebanho bovino comercial do mundo, com cerca de 218,23 milhões de animais, dos quais $10 \%$ são novilhas de dois a três anos e 43\% são vacas (IBGE, 2017).

Porém, no Brasil, a bovinocultura de corte é caracterizada por pouca produtividade e reprodutividade, constituída por alguns detalhes cruciais como a baixa taxa de natalidade, a elevada idade a primeira cria, o percentual reduzido de fêmeas produtivas no rebanho, a elevada idade ao abate e, em destaque, a idade em que se inicia a puberdade das novilhas (Gottschall, 1999).

Segundo Lesmeister et al. (1973), para maximizar a produtividade pecuária no sistema de cria as novilhas Bos taurus taurus devem chegar à puberdade aos 12 meses de idade, emprenhar aos 15 e parir com dois anos de idade. Em novilhas Bos taurus indicus a puberdade ocorre mais tardiamente, entre 18 e 24 meses de idade (Hafez \& Hafez, 2004). Nogueira (2004) afirmou que, em novilhas Bos taurus indicus da raça Nelore, esse evento ocorre ainda mais tardiamente, entre $22 \mathrm{e}$ 36 meses, levando ao aumento da idade ao primeiro parto, que está entre 44-48 meses de idade.

Estudos têm mostrado o quanto é importante observar e trabalhar os fatores que influenciam a a manifestação da puberdade, além de desenvolver alternativas que tornem o processo mais rápido, melhorando a eficiência reprodutiva e o retorno financeiro da produção, chegando na estação de monta com a maior quantidade de novilhas ciclando e aptas para a reprodução.

\section{Mecanismos endócrinos da puberdade}

Mecanismos endócrinos são modificados para garantir que as bezerras no pós-natal não ativem o sistema reprodutivo até que possuam desenvolvimento somático compatível com a reprodução (próximo de $65 \%$ a $70 \%$ do peso adulto) e que sinalize que o gasto de energia para o crescimento e o desenvolvimento já não são prioridades para o seu organismo, permitindo que 
parte dos nutrientes sejam utilizados para gestação, parto e lactação (Semmelmann et al., 2001). Nos bovinos a inibição da atividade reprodutiva é devida à sensibilidade excessiva do hipotálamo ao estrógeno (E2) (Day et al., 1987). A pequena quantidade de estradiol secretada pelos folículos ovarianos após o nascimento das bezerras é suficiente para suprimir a secreção pulsátil de hormônio luteinizante (LH). Day et al. (1984) constataram que, em novilhas pré-puberes ovariectomizadas, houve aumento da frequência e amplitude dos picos de LH, mostrando a possível sensibilização do hipotálamo ao E2 liberado pelos folículos que pertenciam aos ovários extraídos.

A teoria mais aceita entre os pesquisadores para a ocorrência da puberdade é a hipótese gonadostática, segundo a qual a ausência de secreção do hormônio liberador de gonadotrofinas (GnRH) pelo hipotálamo durante a fase prépúbere deve-se à ação do E2, que exerce o efeito de feed back negativo sobre o eixo hipotalâmicohipofisário. Assim, a gradativa redução da sensibilidade do hipotálamo aos efeitos inibitórios do E2, desencadeia o aumento da liberação do GnRH do hipotálamo para a hipófise aumentando a pulsatilidade de LH (Marson et al., 2004). Isso vai resultar no estímulo do crescimento folicular e, posteriormente, na maior produção de E2, levando ao estro e causando uma retroalimentação positiva no hipotálamo, provocando um pico de $\mathrm{GnRH}$, que estimula a hipófise a liberar um pico pré-ovulatório de LH, determinando a ovulação do folículo dominante e formação do corpo lúteo (CL) (Evans et al., 1994; Rawlings et al., 2003).
Para que haja maturação do eixo hipotálamohipófise-gônada é necessário a diminuição do feed back negativo pelo E2 na fase peri-púbere por redução do número de receptores deste hormônio no hipotálamo e na adeno-hipófise, que ocorre progressivamente com o avançar da idade (Day et al., 1987; Day et al., 2010), como pode ser observado na Figura 1. De acordo com Day et al. (1984) essas alterações ocorrem nos 50 dias que antecedem a puberdade, período denominado peripuberdade.

Em novilhas Bos taurus taurus o período do nascimento até a puberdade pode ser dividido em quatro fases de acordo com a mudança fisiológica que há com o avanço da idade desses animais. A primeira fase é a infantil, que vai do nascimento até os dois meses de idade, caracterizada por baixos níveis de LH devido à baixa resposta da hipófise ao GnRH, resposta essa que, com o passar do tempo, vai intensificando. $\mathrm{Na}$ sequência, estabelece-se a fase de desenvolvimento, com faixa etária entre dois e seis meses de idade, em que há maiores concentrações de gonadotrofinas se comparada à fase anterior. Na fase estática, dos seis aos 10 meses de idade, as concentrações de LH estão baixas devido ao aumento anterior de E2 pelas gônadas, provocando a inibição na liberação de gonadotrofinas. A concentração de LH circulante permanece baixa até entrar na fase de peripuberdade, quando ocorrerá a diminuição dos receptores de E2 no hipotálamo e a diminuição do feed back negativo deste hormônio, fazendo com que aumente a liberação de LH que levará à ovulação e à puberdade (Figura 2) (Day et al., 1998).

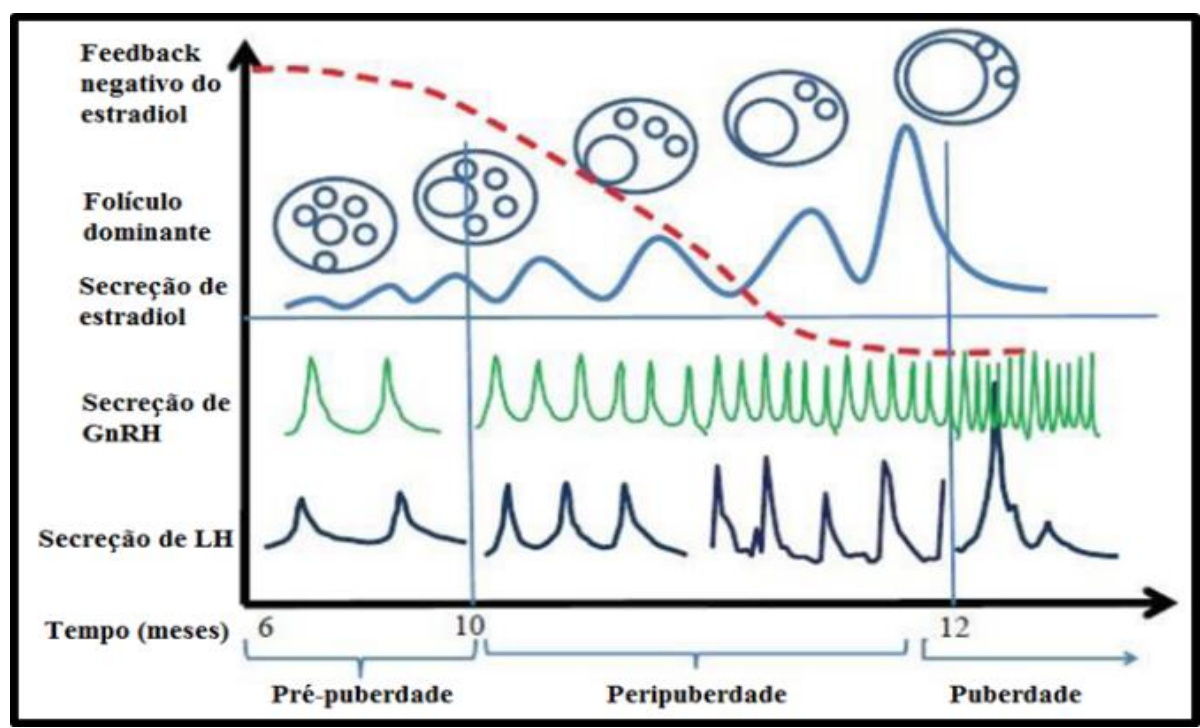

Figura 1. Alterações endócrinas e fisiológicas que precedem a puberdade em novilhas prépúberes. Fonte: Adaptado de Day et al. (2010) 


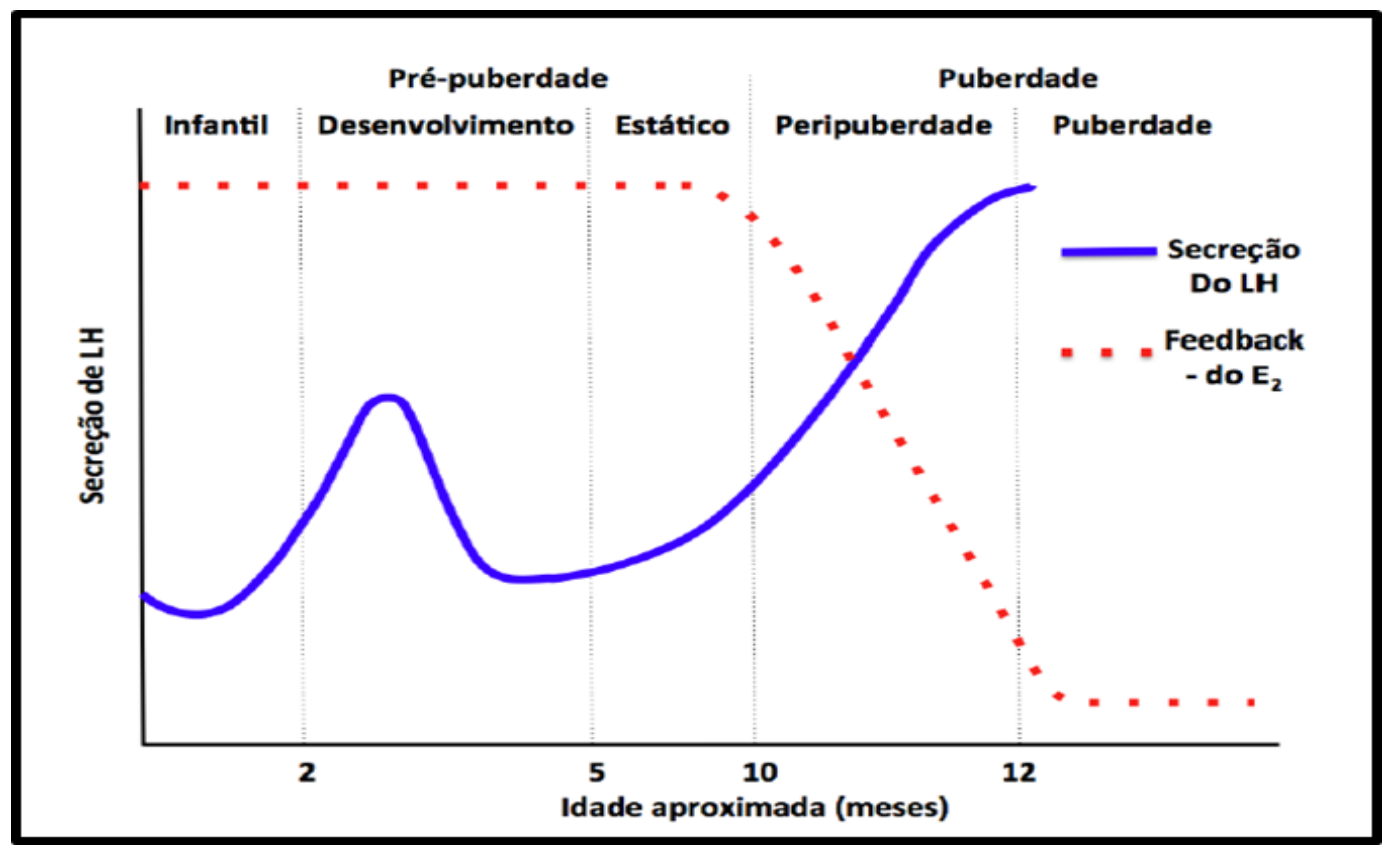

Figura 2. Esquema para os estágios da maturação sexual em novilha. Fonte: Adaptado de Day et al. (2010).

\section{Fatores que influenciam a puberdade}

\section{Genética}

Na novilha, embora exista a dependência de uma idade mínima para a primeira ovulação, relacionada ao ganho de peso do nascimento à puberdade, fatores genéticos e ambientais também influenciam a idade à puberdade (Patterson et al., 1992).

$\mathrm{O}$ produtor que tem como meta emprenhar as novilhas com idade aproximada de um ano para que o primeiro parto ocorra aos dois, deve inserir em sua propriedade uma associação de medidas, dentre elas estão a forma de manejo, nutrição oferecida e seleção genética (Rocha \& Lobato, 2002).

A seleção genética das fêmeas para precocidade, associada a uma boa alimentação desde o nascimento, determina a eficiência das novilhas em ficar prenhe aos 24 meses de idade. Quanto maior a proporção de raças zebuínas no genótipo de novilhas cruzadas, mais tardia a puberdade e com menor probabilidade de emprenharem aos 24 meses, quando comparadas às fêmeas com maior porcentagem de sangue taurino (Rocha \& Lobato, 2002).

Gasser et al. (2006) desenvolveram trabalhos relacionados ao efeito da genética e nutrição e observaram que novilhas Bos taurus taurus que receberam dietas de alto concentrado desde a sua desmama, apresentaram uma taxa média de puberdade precoce (84\%) com 8,7 meses de idade.
O tratamento controle, sem nenhuma modificação na dieta dos animais, obteve uma taxa média de $19 \%$ de puberdade aos 11,6 meses de idade. Já em Bos taurus indicus a puberdade precoce foi de 14 meses de idade (Nogueira, 2004; Nepomuceno, $\underline{2013}$ ).

De acordo com Eler et al. (2010), em relação às características reprodutivas, mais especificamente a puberdade, a maioria dos programas genéticos ainda não avançou $o$ suficiente. Os autores afirmaram que o progresso genético poderia ser maior se a idade ao primeiro parto fosse adotada como principal critério de seleção ao invés do perímetro escrotal, sendo uma característica promissora para avaliar a precocidade de novilhas e de alta herdabilidade.

A proporção de novilhas púberes aos 18 meses de idade é influênciada pelo pai da novilha, de modo que os mesmos transmitem a característica de precocidade para suas filhas. Ao final da primeira estação de monta a proporção de novilhas ciclando aos 18 meses variou de $58,8 \%$ até $0 \%$, mostrando a necessidade de identificar os touros com o melhor potencial de gerar filhas que apresentem puberdade precoce (Nepomuceno, 2013).

\section{Idade}

A idade é um dos principais fatores relacionados à puberdade, caracterizando a precocidade dos animais, portanto tendo sua importância nos programas de seleção genética. 
Em raças zebuínas de corte selecionadas para precocidade sexual, as novilhas podem atingir a puberdade com idade entre 13 e 15 meses. Em novilhas zebuínas criadas a pasto a idade à puberdade varia entre 22 e 36 meses, projetando a idade ao primeiro parto para 4 anos (Souza et al., 1995). Já em animais taurinos, a manifestação da puberdade ocorre normalmente entre 10 a 15 meses (Ferrel, 1982). Nas cruzadas acontece mais tardiamente que nas taurinas e mais precocemente que as zebuínas, evidenciando o efeito da heterose com puberdade por volta dos 15 meses (Restle et al., 1999).

Muitos pesquisadores já relataram a influência da composição genética sobre a idade à puberdade e prenhez na primeira estação de monta. Experimentos conduzidos por Patterson et al. (1991), utilizando novilhas Bos taurus taurus e cruzadas de Bos taurus taurus com Bos taurus indicus, permitiram verificar a maior proporção de novilhas taurinas púberes no início da estação de monta $(93,0 \%$ vs. $67,0 \%$, respectivamente) e maiores taxas de prenhez após 45 dias $(89,0 \%$ vs. $71,0 \%$, respectivamente). Isso indica que animais das raças zebuínas são mais tardios em relação aos taurinos quando se trata da maturação do eixo reprodutivo que permite a manifestação da puberdade.

A idade ao primeiro parto é uma característica que deve ser adotada como critério de seleção, valorizando-se tanto as fêmeas que a manifestam quanto os machos que originam essas fêmeas. A estimativa média de herdabilidade para probabilidade de parto precoce em fêmeas Nelore foi igual a 0,47 (Meirelles, 2004). Já Eler et al. (2002) obtiveram 0,57, o que permite classificar essa característica como sendo de moderada a alta herdabilidade.

Para que a primeira cria ocorra aos dois anos de idade é necessário instituir uma combinação que envolva a alimentação de boa qualidade em todas as fases desde o nascimento, peso ideal e crescimento adequado, de modo que a fêmea possa direcionar a energia para a puberdade e reprodução (Tran et al., 1988).

\section{Nutrição}

A restrição alimentar atrasa o início da puberdade por suprimir a pulsatilidade de LH que é necessária para o crescimento dos folículos ovarianos até o momento pré-ovularório. Essa restrição de nutrientes, além de reduzir a liberação de $\mathrm{LH}$, reduziu as concentrações do fator de crescimento semelhante a insulina 1 (IGF-1), proporcionando menor produção de E2 e a não ovulação (Yelich et al., 1996). Animais em anestro nutricional que estavam em pastagens degradadas e de má qualidade, foram submetidos a realimentação através da mudança para uma pastagem bem manejada e de alta qualidade, levando a apresentarem modificação do sinal metabólico, permitindo o restabelecimento da secreção pulsátil de LH, aumentando o diâmetro do folículo dominante, levando à ovulação (Wettemann et al., 2000).

Novilhas de corte precisam alcançar de 60 a $65 \%$ do peso vivo de um adulto da raça para manifestar a puberdade. Novilhas de reposição devem ser desmamadas com o maior peso possível de acordo com a característica da raça, pois foi demonstrado que aumentar o nível de ganho de peso das novilhas pré-puberes no período pósdesmama antecipa a puberdade, elevando a liberação pulsátil de LH (Bagley, 1993).

Segundo Cardoso et al. (2007), a nutrição afeta a liberação de $\mathrm{GnRH}$ e, consequentemente, de LH, afetando também a ovulação (puberdade). Diferentes fatores parecem influenciar esse mecanismo como a leptina, IGF1, glutamato, ácido gama-aminobutírico (GABA), neuropeptídio Y, inibina e ativina.

Leptina é um hormônio produzido principalmente pelos adipócitos que age sobre o sistema nervoso central sinalizando sobre o estado nutricional e assim regulando o consumo alimentar e o balanço energético (Halaas et al. 1995). Um dos principais papéis da leptina consiste em auxiliar os animais a se adaptarem a condições de subnutrição. Em animais com alimentação inadequada há uma rápida diminuição na concentração de leptina, para estimular a re-alimentação e a secreção de glicocorticoides, diminuição do gasto de energia, diminuição da atividade tireoidiana, sensibilidade à insulina e síntese de proteínas, além de bloquear a reprodução (Ahima et al., 1996; Gui et al., 2003).

Segundo Garcia et al. (2002) e Willians et al. (2002), há relação entre a concentração de leptina com o início da puberdade, permitindo inferir que esse hormônio seria um provável sinal metabólico que comunicaria o estado nutricional à reprodução. De acordo com (Halaas et al. 1995), a leptina é sintetizada e secretada em resposta ao aumento do metabolismo. Portanto, os efeitos da leptina sobre a reprodução são em consequência da disponibilidade de reservas energéticas, já que 
a mesma mandaria sinais a regiões do cérebro sensíveis à glicose, que influenciariam a secreção de GnRH (Amstalden et al., 2000). Novilhas submetidas a restrição nutricional por dois dias, próximas da puberdade, apresentaram diminuição da expressão da leptina no tecido adiposo e na concentração sérica, além de reduzir pulsos de LH (Amstalden et al., 2000).

A presença do neuropeptídio $\mathrm{Y}$ parece influenciar a liberação das gonadotrofinas de forma indireta pela leptina, pelo fato de ser mediador primário e por estimular a liberação basal e cíclica de GnRH, atuando nas mudanças que levam à liberação de LH. A subnutrição aumenta o neuropeptídio $\mathrm{Y}$ que leva à redução do LH (Lebrethon et al., 2000). O neuropeptídio Y está presente no cérebro e atua diretamente nos neurônios do núcleo arqueado, influenciando, dessa forma, o balanço energético, a secreção de GnRH e o comportamento sexual. Essa substância tem sua concentração aumentada quando há restrição alimentar (Gamba et al., 2006; Emerick et al., 2009).

Sabe-se que o início e o progresso da puberdade podem ser influenciados por sinais metabólicos como o IGF-1, uma molécula bioativa cujos níveis circulantes aumentam durante a puberdade e que podem agir na regulação de fatores hipotalâmicos, hipofisários e gonadais envolvidos na maturação sexual (Jones et al., 1991; Clemmons, 1997). A subnutrição pode levar a diminuição da concentração de IGF1 com consequente redução na secreção de $\mathrm{LH}$, contribuindo para o atraso na puberdade (Richards et al., 1991; Srivastava et al., 1995).

\section{Estratégias para antecipar a ocorrência da puberdade}

\section{Bioestimulação}

O efeito da bioestimulação ou efeito-touro tem sido bastante pesquisado como fonte de antecipação da idade à puberdade de novilhas. Este processo consiste em manutenção do macho entre as fêmeas, na fase que antecede a estação de monta, para estimular a atividade reprodutiva pela ativação do eixo hipotalâmico-hipofisáriogonadal (Quadros \& Lobato, 2004).

Feromônios, estimulação genital ou outros estímulos sensitivos provenientes dos demais constituintes do grupo ao qual o animal pertence, ocasionam a bioestimulação, especialmente por potenciais parceiros sexuais, que ao serem percebidos, desencadeiam mudanças em muitos processos fisiológicos e comportamentais incluindo aqueles ligados à reprodução (Roberson et al., 1991). Feromônios são substâncias químicas secretadas e eliminadas na urina, fezes ou glândulas subcutâneas, causando reações específicas em animais da mesma espécie (Rekwot et al. 2001).

O órgão vômero-nasal tem sido proposto como quimiorreceptor especializado envolvido na detecção do estro e na liberação, regulação e coordenação da atividade sexual, devido à presença de conexões nervosas com o hipotálamo. Pode ser o controlador dos efeitos exercidos pelos feromônios que influenciam a função ovariana (Rekwot et al., 2001).

Izard et al. (1982) aplicaram urina de touros como bioestimulante para a indução de puberdade em novilhas pré-púberes taurinas, e água no grupo controle. Obtiveram $67 \%$ de púberes dentro das que passaram pelo tratamento contra $32 \%$ do grupo controle. Relataram que a aplicação oro nasal de urina aumentou a porcentagem de novilhas cíclicas antes da estação de monta.

Quadros et al. (2004) constataram que a implementação da bioestimulação é capaz de alterar o comportamento reprodutivo das novilhas de corte em sua primeira estação de monta. O estudo foi conduzido 50 dias antes da estação de monta, com 60 novilhas de dois anos (Hereford $\mathrm{x}$ Nelore), distribuídas aleatoriamente em dois grupos: bioestimuladas, por meio de um rufião Jersey com desvio lateral de pênis; ou não estimuladas (NE), constituindo o grupo controle. As taxas de novilhas cíclicas antes do início da estação de monta foram de $76,0 \%$ para bioestimuladas e 56\% para NE. As taxas de prenhez foram $90,0 \%$ e $73,0 \%$ no final de estação de monta para bioestimuladas e NE, respectivamente. Os pesquisadores concluíram que a bioestimulação em um período de 50 dias determinou maior taxa de novilhas cíclicas antes de se iniciar a temporada reprodutiva bem como maior taxa de prenhez. A resposta das novilhas ao estímulo da presença do macho é dependente da idade e condição corporal, visto que as novilhas mais velhas emprenharam com facilidade por estarem mais próximas da puberdade, enquanto as novilhas mais jovens, de menor desenvolvimento corporal, possivelmente ainda apresentavam "bloqueio" à completa atividade do eixo hipotalâmico-hipófisario-gonadal, que não pode ser bioestimulado nesse período. 


\section{Protocolos Hormonais}

Com o propósito de reduzir a idade à puberdade em novilhas, vários protocolos têm sido utilizados (Day, 1998). Desta forma esperase aumentar a eficiência reprodutiva do rebanho ao diminuir a idade ao primeiro parto. Estes protocolos consistem na associação, ou não, entre hormônios como: progesterona (P4), GnRH, gonadotrofinas coriônicas humanas (hCG), gonadotrofinas coriônicas equinas (eCG), E2 e prostaglandinas (PGF2 $\alpha$ ).

O fator benefício/custo deve ser favorável ao produtor e condizente com a realidade do rebanho, pois quando essa técnica é usada inadequadamente, compromete os custos da produção prejudicando a relação investimentos/resultados, inviabilizando o procedimento (Pfeifer et al., 2009).

Progestágenos são compostos similares a P4, que podem ser administrados por via oral (acetato de melenguestrol - MGA), implantes subcutâneos de norgestomet (Crestar $\AA$ ) ou dispositivos intravaginais contendo $\mathrm{P} 4$ (CIDR ${ }^{\circledR}, \quad \mathrm{DIB} \AA$ e PRID®). O uso destes compostos diminui a quantidade de receptores de E2 no hipotálamo, o que reduz a retroalimentação negativa desse hormônio sobre a liberação de GnRH, ocasionando aumento na liberação de LH. Este é o mecanismo responsável pela indução da puberdade nos tratamentos com progestinas (Day et al., 1998).

De acordo com Nogueira et al. (2004), as novilhas peri-púberes tiveram ciclos estrais curtos, caracterizados pela luteólise prematura. Foi relatado também que a fertilidade é maior no terceiro estro após o início da puberdade. Devido a esse processo fisiológico de maturação póspuberdade, a novilha pré-púbere recém-chegada na estação de monta fica limitada quanto à sua fertilidade. Por isso, é necessário que chegue na estação de monta já ciclando, o que pode incrementar o índice de prenhez.

A hormonioterapia tem beneficiado a sincronização e a indução da puberdade em novilhas pré-púberes e a utilização da primeira ovulação, de menor fertilidade, em programas de IATF, ou antecipação da ocorrência da terceira ovulação, que possui maior fertilidade (Patterson \& Brethor, 1990).

Segundo Azeredo et al. (2007), o sucesso do efeito da hormonioterapia é dependente da raça, idade e peso no momento da aplicação. E $\underline{\text { Hall et }}$ al. (1997) verificaram que a indução da puberdade está associada ao peso corporal e que novilhas mais pesadas respondem melhor ao tratamento.

Um fator importante relacionado à puberdade induzida por P4 é o efeito dose e/ou tempo de exposição ao progestágeno, principalmente quando trabalhar com novilhas de origem zebuína. Altas doses ou período prolongado de exposição a P4 são relacionadas a baixos índices de prenhez (Bergfeld et al., 1996), devido ao fato de zebuínos apresentarem menor velocidade metabólica da P4 em relação a taurinos. De acordo com $\underline{\text { Sá filho \& }}$ Vasconcelos (2008), em Bos taurus indicus, altas concentrações iniciais de $\mathrm{P} 4$ diminuem a secreção pulsátil do LH, reduzindo a secreção de androstenediona pelas células da teca e o crescimento folicular, causando diminuição da secreção de estradiol pelas células da granulosa do folículo dominante e, consequentemente, afetando o processo ovulatório.

\section{Norgestomet}

Anderson et al. (1996) realizaram dois experimentos para avaliar o mecanismo pelo qual a exposição a progestágenos poderiam induzir a puberdade em novilhas pré-púberes. No primeiro experimento, por um período de 10 dias, 15 novilhas receberam um implante de Norgestomet, e 14 novilhas ficaram sem o implante. Amostras de sangue foram coletadas para avaliar a pulsatilidade de LH. Tanto a taxa de animais púberes $(85,7 \%)$ quanto a frequência dos pulsos de LH foram superiores nas novilhas tratadas em relação às novilhas controle $(0 \%)$. No segundo experimento foram utilizados zero, um ou três implantes de Norgestomet por 10 dias e o sangue foi coletado para análises de concentração de progesterona. A puberdade foi induzida em $75,0 \%$ das novilhas tratadas com um implante e $81 \%$ das tratadas com três implantes de Norgestomet. A frequência dos pulsos de LH foi suprimida durante o tratamento das novilhas com três implantes, mas foi maior durante 12 horas após a remoção do implante, quando comparado ao grupo controle.

Os resultados obtidos sugerem que $o$ mecanismo pelo qual as progestinas induziram a puberdade seria por diminuir os receptores de E2 no hipotálamo, reduzindo o feed back negativo do E2 sobre a liberação de GnRH, que por sua vez aumentou a pulsatilidade de LH, proporcionando crescimento folicular, maior produção de estradiol pelos folículos ovarianos e o pico pré-ovulatório de LH, ocasionando a ovulação (Day et al., 1998). 


\section{Acetato de Melenguestrol (MGA)}

$\mathrm{O}$ acetato de melenguestrol (MGA) é um composto progestacional de adminstração por via oral, que vem sendo utilizado para a indução da puberdade. Patterson et al. (1996) forneceram para 60 novilhas pré-púberes $0,5 \mathrm{mg} / \mathrm{dia} /$ cabeça durante sete dias, e constataram que $67 \%$ das fêmeas apresentaram estro após o encerramento do tratamento e $60 \%$ dos animais tinham concentração plasmática de progesterona acima de $1 \mathrm{ng} / \mathrm{ml}$, mostrando a presença de um CL de vida normal após 14 dias de interrupção da hormonioterapia.

Imwalle et al. (1998) testaram o efeito do MGA administrado durante oito dias em novilhas Nelore pré-púberes no intuito de avaliar se o hormônio estimularia a liberação de LH e crescimento folicular. A ciclicidade foi observada monitorando as concentrações de $\mathrm{P} 4 \mathrm{e}$ as estruturas ovarianas por 14 dias após o tratamento. Os autores afirmaram que nas oito novilhas pré-púberes tratadas com MGA houve aumento nos pulsos de LH durante o tratamento, e que todas as novilhas tornaram-se púberes nos 10 dias posteriores ao fim do tratamento. Já nas nove novilhas controle, não houve alteração no comportamento do LH durante o período experimental e no final do experimento somente quatro novilhas apresentaram-se púberes. Em relação ao diâmetro folicular, constatou-se o aumento no diâmetro do maior folículo nas novilhas tratadas com MGA, o que não foi observado nas novilhas controle.

Patterson et al. (1990) compararam o efeito do tratamento de sete dias com MGA e MGA com aplicação de $\mathrm{GnRH}$ em novilhas pré-puberes Bos taurus taurus x Bos taurus indicus, revelando que a resposta estral foi a mesma entre os tratamentos e entre raças, ambos levando à indução da puberdade.

Jaeger et al. (1992) testaram o efeito do MGA por 14 dias + PGF2 $\alpha$. Os resultados revelaram que $37 \%$ (55/147) dos animais eram pré-púberes antes do início do tratamento com MGA e, deste grupo, $72 \%(40 / 55)$ das novilhas atingiram a puberdade durante ou após a ingestão do MGA. Das mesmas que atingiram a puberdade, $82 \%$ (33/40) apresentaram estro após PGF2 e foram inseminadas, obtendo uma taxa de concepção à primeira inseminação de 66\% (22/33). Conclui-se que a combinação de MGA + PGF2 $\alpha$ é uma estratégia hormonal para induzir puberdade e também não compromete a fertilidade na primeira inseminação.

\section{Implante Vaginal de Progesterona}

Rasby et al. (1998) realizaram um estudo testando os efeitos do implante vaginal (CIDR $®$ ) contendo 1,9 gramas de $\mathrm{P} 4$ por sete dias, ou em combinação com o benzoato de estradiol (BE) entre 24 a 30 horas após a remoção do implante, para a indução da puberdade. Os resultados demonstraram que as novilhas pré-púberes tratadas tiveram maior taxa de manifestação de estro do que os animais controle entre zero e 10 dias após a retirada do implante (80\% CIDR; $94 \%$ CIDR + BE; 40\% controle). Observaram que 114 das 203 novilhas pré-púberes desenvolveram CL funcional sem ciclo de curta duração. A administração de $\mathrm{BE}$ ao protocolo promoveu indução de picos pré-ovulatórios de LH e FSH. Elevada concentração de estradiol na circulação substitui o mecanismo de feedback negativo no hipotálamo e hipófise e provoca um feedback positivo que induz a liberação de LH. Os autores concluíram que associação de P4 com E2 é eficiente para a indução da puberdade em novilhas pré-púberes de corte.

Pfeifer et al. (2009) avaliaram o efeito de um tratamento curto de sincronização com implante vaginal durante cinco dias, com ou sem uso de PGF2 $\alpha$ (500 mg de cloprostenol, intramuscular) no dia da retirada do implante em novilhas prépúbres. Foi observado que os animais que foram tratados com P4 + PGF2 apresentaram maior taxa de ovulação $(72,7 \%)$ em comparação com os animais tratados somente com P4 $(30,8 \%)$ e também em comparação com o grupo controle $(7,1 \%)$. Além disso, nenhuma das novilhas que foram tratadas apresentou ciclo estral curto após a ovulação. Os autores inferiram que novilhas tratadas com implante de $\mathrm{P} 4$, em associação com PGF2 $\alpha$, ovularam de forma mais eficaz que nos outros tratamentos. Acrescentaram ainda que o mecanismo responsável é um aumento da sensibilidade da hipófise ao GnRH em decorrência da aplicação de PGF2 $\alpha$. Estudos sugerem um efeito direto de PGF2 $\alpha$ na hipófise anterior, aparentemente melhorando a resposta pituitária ao GnRH e assim aumentando a liberação de LH.

Claro Júnior et al. (2010) avaliaram o efeito da exposição de novilhas Nelore pré-púberes a diferentes concentrações de P4, através do implante vaginal contendo P4 (CIDR $®)$, na antecipação da puberdade, determinada pela detecção de cio, concepção e prenhez em sete, 45 e 90 dias de estação de monta. Utilizaram 589 novilhas Nelore pré-púberes que foram 
aleatoriamente divididas para cada grupo: CIDR0, nenhum tratamento (controle); CDR1, CIDR ${ }^{\circledR}$ de primeiro uso; CIDR4, CIDR® de quarto uso (previamente utilizado por 27 dias). As novilhas permaneceram com o dispositivo intravaginal de P4 por 12 dias, foram observadas para detecção de cio durante 45 dias e, após este período, foram expostas a touros para monta natural. As novilhas que já estavam ciclando receberam uma dose de PGF2 $\alpha$ e foram observadas em cio juntamente com as novilhas induzidas (Figura 3 ).

Os autores observaram que na primeira colheita de sangue (d-19) 8,6\% das novilhas prépúberes apesentavam concentrações séricas de $\mathrm{P} 4$ acima de $1,0 \mathrm{ng} / \mathrm{ml}$ e que na segunda colheita (d12) houve aumento de animais sem presença de $\mathrm{CL}$, mas com P4 acima de $1,0 \mathrm{ng} / \mathrm{ml}$ (falsopositivos). Devido a isso, foi aumentado o critério de puberdade para $1,5 \mathrm{ng} / \mathrm{ml}$ de $\mathrm{P} 4$ em novilhas Nelore, para ter maior chance de acerto. No dia 0 do experimento as concentrações séricas de P4 estavam maiores para as novilhas tratadas com CIDR $®$ independentemente do número de uso. A diferença observada no diâmetro de maior folículo no dia 0 deve-se à pulsatilidade de $\mathrm{LH}$, de modo que doses sub-luteais de P4 estimularam a liberação pulsátil de LH e, por consequência, o crescimento do folículo dominante e maior liberação de E2, explicando o maior diâmetro folicular observado no uso do CIDR ${ }^{\circledR}$ de quarto uso. Embora a concentração de estradiol não tenha sido avaliada no referido estudo, os autores suspeitaram que o uso do CIDR® de quarto uso nas novilhas resultou em maior concentração de $\mathrm{E} 2$, já que apresentaram maior diâmetro folicular e desenvolvimento uterino.

O tratamento nas novilhas pré-púberes surtiu efeito na taxa de concepção em sete dias de estação de monta (EM), de modo que os animais que receberam o CIDR ${ }^{\circledR}$ de quarto uso tiveram maior pulsatilidade de LH. Acredita-se que a maior taxa de concepção ocorreu devido ao diâmetro folicular e desenvolvimento uterino, que foram maiores que nos outros tratamentos. Animais que ovulam folículos maiores apresentam maior corpo lúteo, consequentemente maior produção de $\mathrm{P} 4$ no diestro, sendo fundamental ao desenvolvimento embrionário (Vasconcelos et al., 2001). Em relação ao escore uterino, Montanholi et al. (2004), em estudos com novilhas, concluíram que animais com escore do aparelho reprodutivo menor que três, em uma escala de zero a cinco, tiveram taxas de prenhez de 10 a $20 \%$ menores que os classificados em escores maiores.

Segundo os autores, os resultados indicam que novilhas induzidas com o CIDR $®$ de primeiro ou quarto uso apresentaram mais cio e tiveram maior prenhez em relação às novilhas controle. A taxa de concepção à primeira inseminação artificial (IA) foi semelhante entre as novilhas induzidas com o CIDR ${ }^{\circledR}$ de quarto uso e as novilhas ciclando. Entre as novilhas induzidas com CIDR ${ }^{\circledR}$ de primeiro ou quarto uso, a taxa de prenhez final não diferiu, sendo que as novilhas do grupo controle tiveram menor prenhez ao final da EM (Tabela 1).

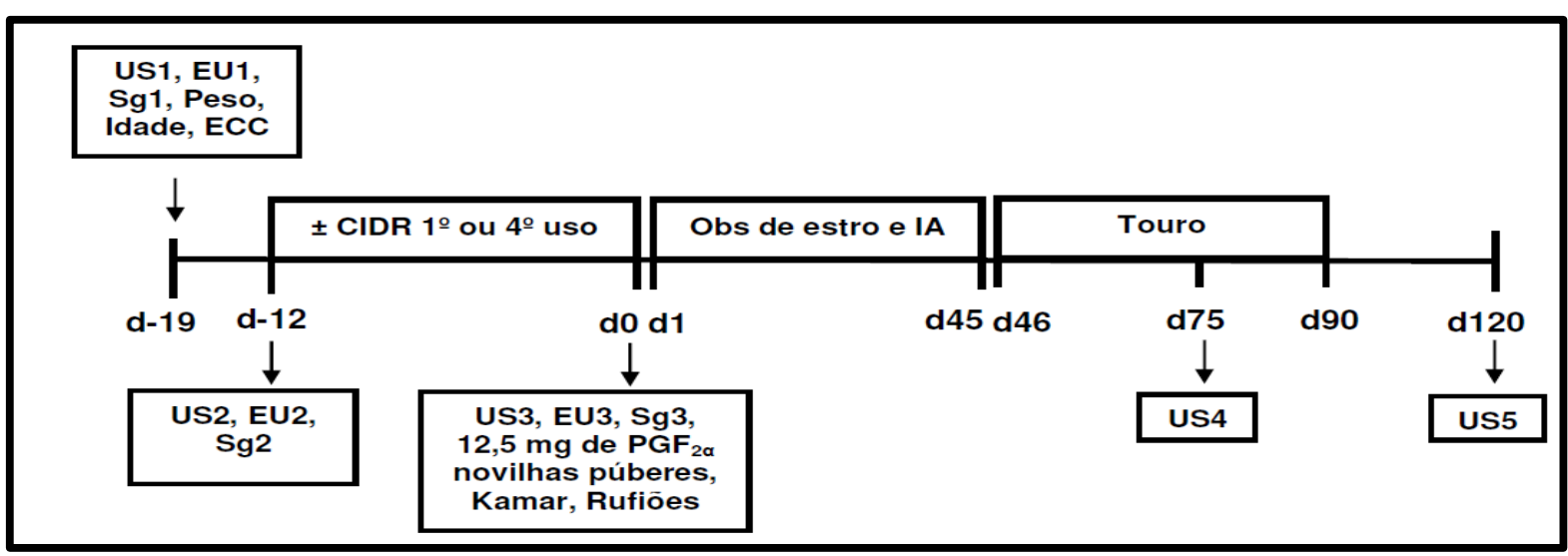

Figura 3. Diagrama esquemático do experimento com CIDR $®$ de primeiro e quarto uso. Fonte: Claro Júnior et al. (2010). US, ultrassonografia; Sg, colheita de sangue; EU, escore de útero; ECC, escore de condição corporal. d-19: US1 - para avaliação da presença de CL; EU1; Sg1 - dosagem de P4; ECC; pesagem; avaliação da idade (mês e ano do nascimento). d12: US2 - para avaliação da presença de CL; EU2; Sg2 - dosagem de P4; inserção do dispositivo intravaginal contendo P4 novo (primeiro uso) ou utilizado previamente por 27 dias (quarto uso) em parte das novilhas sem CL (pré-púberes). d-0: US3 - medida do diâmetro do maior folículo; EU3; Sg3 - coleta de sangue em 100\% dos animais; 12,5 mg de PGF2 $\alpha$ nas novilhas consideradas púberes; Kamar - colocação do dispositivo para ajudar na detecção do estro. d-1: início da observação de estro. d-45: último dia de observação do estro. d-46: exposição das novilhas aos touros. d-75: US4 - diagnóstico de gestação. d-90: fim da estação de monta. d-120: US5- diagnóstico de gestação final da estação de monta. 
Tabela 1. Resultados reprodutivos das novilhas Nelore nos diferentes tratamentos relacionados ao número de uso do CIDR ${ }^{\circledR}$

\begin{tabular}{|c|c|c|c|c|}
\hline \multirow[b]{2}{*}{ Variável Dependente } & \multicolumn{4}{|c|}{ Tratamentos } \\
\hline & $\begin{array}{l}\text { CIDR } 0 \\
(n=113)\end{array}$ & $\begin{array}{l}\text { CIDR 1 } \\
(n=237)\end{array}$ & $\begin{array}{l}\text { CIDR } 4 \\
(n=239)\end{array}$ & $\begin{array}{c}\text { PGF } \\
(n=346)\end{array}$ \\
\hline Estro em 45 dias, $\%$ & $52,2^{\mathrm{A}}$ & $72,1^{\mathrm{B}}$ & $75,3^{\mathrm{B}}$ & $89,0^{\mathrm{C}}$ \\
\hline Concepção à primeira IA em 45 dias, \% & $35,6^{\mathrm{A}}$ & $35,1^{\mathrm{A}}$ & $45,0^{\mathrm{BA}}$ & $51,8^{\mathrm{B}}$ \\
\hline Prenhez de IA em 45 dias, $\%$ & $27,4^{\mathrm{A}}$ & $39,2^{\mathrm{B}}$ & $47,7^{\mathrm{C}}$ & $70,1^{\mathrm{D}}$ \\
\hline Gestação em EM, \% & $72,4^{\mathrm{A}}$ & $83,7^{\mathrm{B}}$ & $83,8^{\mathrm{B}}$ & $92,6^{\mathrm{C}}$ \\
\hline
\end{tabular}

Fonte: Claro Júnior et al. (2010).

Rodrigues et al. (2014) testaram um protocolo de indução de puberdade seguido por um protocolo de sincronização do estro em novilhas pré-púberes. Quando a IATF foi iniciada 12 dias após a indução de puberdade, o diâmetro folicular, taxas de concepção e prenhez foram maiores em relação às novilhas sincronizadas com 10 ou 14 dias após a indução da puberdade. Os autores justificaram que o intervalo de 12 dias proporcionou um melhor período de proestro, criando melhor ambiente uterino e melhor desenvolvimento folicular. Os resultados estão demonstrados na (Tabela 2).

Tabela 2. Diâmetro folicular nos dias 9 e 11, taxas de ovulação, concepção e prenhez de novilhas submetidas à inseminação artificial em tempo fixo em diferentes dias após a indução da primeira ovulação

\begin{tabular}{lrrr}
\hline Variáveis & Grupo 10 & \multicolumn{1}{l}{ Grupo } & \multicolumn{2}{l}{ Grupo } \\
& & 12 & \multicolumn{2}{c}{14} \\
\hline Diâmetro folicular dia 9, mm & 9,31 & 9,96 & 9,92 \\
Diâmetro folicular dia 11, mm & 10,96 & 10,96 & 11,17 \\
Ovulação, \% & 85,70 & 87,80 & 87,20 \\
Concepção, \% & 39,20 & 52,10 & 47,40 \\
Prenhez, \% & 33,10 & 45,20 & 40,30
\end{tabular}

Fonte: Rodrigues et al. (2014)

\section{Considerações finais}

No início da estação reprodutiva, fatores e estratégias que aumentem a proporção de novilhas ciclando e sexualmente maduras devem ser entendidos como importantes ferramentas de manejo reprodutivo a serem instituídas nas propriedades de cria. A elevação da proporção de novilhas púberes causa um impacto bastante significativo na lucratividade da propriedade, possibilitando a obtenção de maior número de bezerros, maior longevidade da novilha e melhoria do desempenho do rebanho com o incremento genético dessas novilhas aptas à reprodução. Novilhas pré-púberes no início da estação de monta são um entrave à eficiência da produção, pois retardam a reprodução.
A nutrição com suplementação estratégica das bezerras, o melhoramento genético, a bioestimulação e os tratamentos hormonais são ferramentas que estão à disposição de técnicos e produtores e que permitem antecipar a puberdade de novilhas, devendo-se avaliar o benefício-custo de cada alternativa bem como as particularidades de cada propriedade e sistema de criação.

\section{Referências bibliográficas}

Anderson, L. H., Mcdowell, C. M., Day, M. L. 1996. Progestininduced puberty and secretion of luteinizing hormone in heifers. Biology of Reproduction, 54,1025-1031.

Ahima, R. S., Prabakaran, D., Mantzoros, C., Lowell, B., Maratos-Flier, E., Flier, F. 1996. Role of leptin in the neuroendocrine response to fasting; Nature; p. 250-252, 382.

Amstalden, M., Garcia, M. R., Williams, S. W., Stanko, R. L., Nizielski, S. E., Morrison, C. D., Keisler, D. H., Williams, G.L. 2000. Leptin gene expression,circulating leptin and luteinizing hormone pulsatility are acutely responsive to short-term fasting in prepubertal heifers: relationships to circulating insulin and insulin-like growth factor. Biology of reproduction., 63, 127-133.

Azeredo, D. M., Rocha, D. C., Jobim, M. I. M., Mattos, R. C., Gregory, R. M. 2007. Efeito da sincronização e da indução de estros em novilhas sobre a prenhez e o índice de repetição de crias na segunda estação reprodutiva. Ciência Rural, 37, 201-205.

Bagley, C. P. Nutritional management of replacement beef heifers - a review. Journal of Animal Science, 71, n. 11, 3155 - 3163, 1993.

Bergfeld, E. G. M., Kojima, F. N., Cup, A. S., Wehrman, M. E., Peters, K. E., Mariscal, V., Sanchez, T., Kinder, J. E. 1996. Changing dose of progesterone results in sudden changes in frequency of luteinizing hormone pulses 
secretion of $17 \beta$-estradiol in bovine females. Biology of Reproduction, 54, 546-553.

Cardoso, D., Nogueira, G. P. 2007. Mecanismos neuroendócrinos envolvidos na puberdade de novilhas. Arquivos de Ciências Veterinárias e Zoologia da Unipar, 10, n. 1, 59-67.

Claro Júnior, I., Peres R. F. G., Aono F. H; Day M. L., Vasconcelos J. L. M. 2010. Reproductive performance of prepubertal Bos indicus heifers after progesterone-based treatments. Theriogenology. v. 74, 903-11.

Clemmons, D. R. 1997. Insulin-like growth factor binding proteins and their role in controlling IGF actions. Cytokine Growth Factor Reviews., 8, 45-62.

Day, M. L., Anderson, L. H. 1998. Current concepts on the control of puberty in cattle. Journal of Animal Science, 76, 1-15.

Day, M. L., Gasser, C. L., Grum, D. E., Pires, A. V. 2010. Fatores que afetam a idade na puberdade em novilhas de corte. In: Pires, A. V. (Ed). Bovinocultura de corte. Piracicaba: Fealq, 637-652.

Day, M. L., Imakawa, K., Garcia-Winder, M., Zalesky, D. D., Schanbacher, B. D., Kittok, R. J., Kinder, J. E. 1984. Endocrine mechanisms of puberty in heifers. Estradiol negative feedback regulation of luteinizing hormone secretion. Biology of Reproduction, 31, 332341.

Day, M. L., Imakawa, K., Wolfe, P. L., Kikttok, R. J., Kinder, J. E. 1987. Endocrine mechanisms of puberty in heifers. Role of hypothalamo-pituitary estradiol receptors in the negative feedback of estradiol luteinizing hormone secretion. Biology of Reproduction, 37, 1054-1065.

Eler, J. P., Ferraz, J. B. S., Teixeira, L. A. 2010. Seleção para precocidade sexual em novilhas de corte. In: PIRES, A. V. (Ed). Bovinocultura de corte. Piracicaba: Fealq, 801-811.

Eler, J. P., Silva, J. A., Ferraz, J. B. S., Dias, F; Oliveria, H. N., Evans, J. L., Golden, B. L. 2002. Genetic evaluation of the probability of pregnancy at 14 months for Nellore heifers. Journal of Animal Science, 80, 951-954.

Emerick, L. L., Dias J. C., Gonçalves P. E. M., Martins J. A. M., Leite T. G., Andrade, V. J., Vale Filho R. V. 2009. Aspectos relevantes sobre a puberdade em fêmeas. Revista Brasileira de Reprodução Animal, 33, n. 1, 1119.
Evans, A. C. O., Adams, G. P., Rawlings, N. C. 1994. Endocrine and ovarian follicular changes leading up to the first ovulation in prepubertal heifers. Journal of Reproduction and Fertility, 100, 187-194.

Ferrel, C. L. 1982. Effects of post-weaning rate of gain on onset of puberty and productive performance of heifers of different breeds. Journal of Animal Science, 55, 1272-1283.

Gamba, M., Pralong, F. P. 2006. Control of GnRH neuronal activity by metabolic factors: the role of leptin and insulin. Molecular and Cellular Endocrinology, 254-255:133-139.

Garcia, M. R., Amstalden, M., Willians, S. W., Stanko, R. L., Morrison, C. D., Keisler, D. H., Nizielski, S. E., Willians, G. L. 2002. Serum leptin and its adipose gene expression during pubertal development, the estrous cycle, and different seasons in cattle. Journal Animal Science, 60, 2158-2167.

Gasser, C. L., Behlke, E. J., Grum, D. E., Day, M. L. 2006. Effect of timing of feeding high concentrate diet on growth and attainment of puberty in early-weaned heifers. Journal of Animal Science, n. 84, p 3118-3122.

Gottschall, C. S. 1999. Desempenho reprodutivo de novilhas submetidas a um programa de sincronização de cios e avaliação do trato reprodutivo. Arquivos da Faculdade de Veterinária UFRGS, 27, n. 1, 21-33.

Gui, Y., Silha, J. V., Mishira, S., Murphy, L. J. 2003. Changes in adipokine expression during food deprivation in the mouse and relationschips to fasting-induced insulin resistance. Canadian Journal of Physiology and Pharmacology, 81, 979-85.

Hafez, E. S. E., Hafez, B. 2004. Reprodução Animal. 7. ed. São Paulo: Manole, 530 pg.

Halaas, J., Gajiwala, K., Maffei, M., Cohens, S., Chait, B., Rabinowitz, D., Lallone, R., Burley, S., Friedman, J. 1995. Weight-reducing effects of the plasma protein encoded by the obese gene. Science, 269, 543-546.

Hall, J. B., Staigmiller, R. B., Short, R. E., Bellows, R. A., Macneil, M. D., Bellows, S. E. 1997. Effect of age and pattern of gain on induction of puberty with a progestin in beef heifers. Journal of Animal Science, 75, 16061611.

IBGE - Instituto Brasileiro de Geografia e Estatística. 2017. Disponível em: httl: 
//www.ibge.gov.br. Acesso em: 23 abr. de 2018.

Imwalle, D. B., Patterson, D. J., Schillo, K. K. 1998. Effects of melengestrol acetate on onset of puberty, follicular growth, and patterns of luteinizing hormone secretion in beef heifers. Biology of Reproduction, 58, 1432-1436.

Izard, M. K., Vandenbergh, J. G. 1982. The effects of bull urine on puberty and calving date in crossbred beef heifers. Journal of Animal Science, 5, 55, 1160-68.

Jaeger, J. R., Whittier J. C., Corah L. R., Meiske J. C., Olson K. C., PATTERSON D. J. 1992. Reproductive response of yearling beef heifers to a melengestrol acetate-prostaglandin F2 alpha estrus synchronization system. Journal of Animal Science, 70, 2622-2627.

Jones J.I., D'Ercole A.J., Camacho-Hubner C. \& Clemmons D.R. 1991. Phosphorylation of insulin-like growth factor-binding protein in cell culture and in vivo: effects on affinity for IGF-I. Proceedings of the National Academy of Sciences of the USA. 88 7481-7485.

Lebrethon, M. C., Vandersmissen, E., Gerard, A., Parent, A. S., Junien, J. L., Bourguignon, J. P. 2000. In Vitro stimulation of the prepubertal rat gonadotropin-releasing hormone pulse generator by leptin and neuropeptide $\mathrm{Y}$ though distinct mechanisms. Endocrinology, 141, 1464-1469.

Lesmeister, J. L. 1973. Date of first calving in beef cows and subsequent calf production. Journal of Animal Science, 36, 1-6.

Marson, E. P., Guimarães, J. D., Miranda Neto, T. 2004. Puberdade e maturidade sexual em novilhas de corte. Revista Brasileira de Reprodução Animal, 28, 1-64.

Meirelles, S. L., Espasandin, A. C., Mattar, M., Queiroz, S. A. 2009. Genetic and environmental effects on sexual precocity traits in Nellore cattle. Revista Brasileira de Zootecnia, 38, 1488-1493.

Montanholi, Y. R., Barcellos, J. O. J., Borges, J. B., Costa, E. C., Wunsh, C., Prates, E. R. 2004. Ganho de peso na recria e desempenho reprodutivo de novilhas acasaladas com sobreano. Pesquisa Agropecuária Brasileira, 39 , n. 12, 1253-1259.

Nepomuceno, D. D., Pires, A. V., Ferraz Junior, M. V. C., Biehl, M. V., Goncalves, J. R. S., Moreira, E. M., Day, M. L. 2017. Effect of pre-partum dam supplementation, creep- feeding and post-weaning feedlot on age at puberty in Nellore heifers. Livestock Science, 195, 58-62.

Nogueira, G. P. 2004. Puberty in South America Bos indicus cattle. Animal Reproduction Science, 82-83, 361-372.

Patterson, D. J., Corah L. R., Simms D. D. 1996. Reproductive performance of $\mathrm{F} 1$ Angus $\mathrm{x}$ Hereford and F1 Brahman x Hereford heifers fed to prebreeding target weights. Journal of Animal Science, 63, 386.

Patterson, D. J., Corah L. R., Brethour, J. R. 1990. Response of prepubertal Bos Taurus and Bos indicus $\mathrm{x}$ Bos Taurus heifers to melengestrol acetate with or without gonadotropin-releasing hormone. Theriogenology, 33, 661-668.

Patterson, D. J., Corah L. R., Brethour, J. R., Spire, M. F., Higgings, J. J., Kiracofe, G. H, Stevenson, J. S., Simms, D. D. 1991. Evaluation of reproductive traits in Bos Taurus and Bos indicus crossbred heifers: effects of postweaning energy manipulation. Journal of Animal Science, 69, 2349-2361.

Patterson, D. J., Perry, R. C., Kiracofe, G. H., Bellows, R. A., Staigmiller, R. B., Corah, L. R. 1992. Management considerations in heifer development and puberty. Journal of Animal Science, 70, 4018-4035.

Pfeifer, L. F. M., Siqueira, L. G., Mapletoft R. J., Kastelic J. P., Adams G. P., Colazo M. G., Singh J. 2009. Effect of exogenous progesterone and cloprostenol on ovarian follicular development and first ovulation in prepubertal heifers. Theriogenology, 72, 10541064.

Quadros, A. S. F., Lobato, J. F. P. 2004. Bioestimulação e comportamento reprodutivo de novilhas de corte. Revista Brasileira de Zootecnia, 33, n. 3, 679-683.

Rasby, R. J., Day, M. L., Johnson, S. K., Kinder, J. E., Lynch J. M., Short, R. E., Wetteman, R. P., Hafs H. D. 1998. Luteal function and estrus in peripubertal beef heifers treated with an intravaginal progesterone releasing device with or without a subsequent injection of estradiol. Theriogenology, 50, 55-63.

Rawlings, N. C., Evans, A. C., Honoramooz, A., Bartlewski, P. M. 2003. Antral follicle growth and endocrine changes in prepubertal cattle, sheep and goats. Animal Reproduction Science, 78, 259-270. 
Restle, J., Polli, V. A., De Senna, D. B. 1999. Efeito de grupo genético e heterose sobre a idade e peso á puberdade e sobre o desempenho reprodutivo de novilhas de corte. Pesquisa Agropecuária Brasileira, 34, n. 4, 701-707.

Rekwot, P. I., Ogwu, D., Oyedipe, E. O., Sekoni, V. O. 2001. The role of pheromones and biostimulation in animal reproduction. Animal Reproduction Science, 65, 157-70.

Richards, M. W., Wettemann, R. P., Spicer, L. J., Morgan, G. L. 1991. Nutritional anestrus in beef cows: effects of body condition and ovariectomy on serum LH and IGF-1. Biology of Reproduction, 44, 961-996.

Roberson, M. S., Wolf, W. M., Stumpf, T. T., Werth, L. A., Cupp, S. A., Kojima, N., Wolfe, P. L., Kittok, R. J., Kinder, J. E. 1991. Influence of growth rate and exposure bulls on age at puberty in beef heifers. Journal of Animal Science, 69, 2092-2098.

Rocha, M. G., Lobato, J. F. P. 2002. Avaliação do desempenho reprodutivo de novilhas de corte primíparas aos dois anos de idade. Revista Brasileira de Zootecnia, 31, n. 3, 1388-1395.

Rodrigues, A. D. P., Peres, R. F. G., Lemes, A. P., Martins, T., Pereira, M. H. C., Carvalho, E. R., Day, M. L., Vasconcelos, J. L. M. 2014. Effect of interval from induction of puberty to initiation of a timed AI protocol on pregnancy rate in Nelore heifers. Theriogenology, 82, 761-766.

Sá Filho, O.G., Vasconcelos, J.L.M. 2008. Regressão prematura do corpo lúteo em bovinos. Revista Veterinária e Zootecnia, 15,220-233.

Semmelmann, C. E. N., Lobato, J. F. P., Rocha, M. G. 2001. Efeito de sistemas de alimentação no ganho de peso e desempenho reprodutivo de novilhas Nelore acasaladas aos 17/18 meses. Revista Brasileira de Zootecnia, 30, n. 3, 835843.

Souza, E. M., J. C. Milagres, M. A. Silva, A. J. Regazzi e A. G. C. Castro. 1995. Influências genéticas e de meio ambiente sobre a idade ao primeiro parto em rebanhos de Gir leiteiro. Revista Sociedade Brasileira Zootecnia. v. 24, n 6, 926-935.

Srivastava, V., Hiney, J. K., Nynerg, C. L., Dees, W. L., 1995. The effect of ethanol on the synthesis of insulin-like growth factor-1(IGF1) and the IGF-1 receptor in late oreoubertal female rats: A correlation with serum IGF-1. Alcoholism Clinical and Experimental Research, 19, 1467-1473.

Tran, T. Q., Warnick, A. C., Hammond, M. E., Koger, M. 1988. Reproduction in Brahman cows calving for the first time at two or three years of age. Theriogenology, 29, 751-756.

Vasconcelos, J. L. M., Sartori, R., Oliveira, H. N., Guenther, J. N., Wiltbank, M. C. 2001. Reduction in size of the ovulatory follicle reduces subsequent luteal size and pregnancy rates. Theriogenology, 56, 307-314.

Wettemann, R. P., Bossis, I. 2000. Energy intake regulates ovarian function in beef cattle. Journal of Animal Science, 77, 1-10.

Willians, G. L., Amstalden, M., Garcia, M. R., Stanko, R. L., Nizielski, S. E., Morrison, C. D., Keisler, D. H. 2002. Leptin and its role in the central regulation of reproduction in cattle. Domestic Animal Endocrinology, 23, 339-349.

Yelich, J. V., Wettermann, R. P., Marston, T. T., Spicer, L. J. 1996. Luteinizing hormone, growth hormone, insulin like growth factor-1, insulin and metabolites before puberty in heifers fed to gain at two rates. Domestic Animal Endocrinology, 13, n. 4, 325-338.

Recebido: 21 setembro, 2018

Aprovado: 20 outubro, 2018.

Publicado: 26 dezembro, 2018.

Licenciamento: Este artigo é publicado na modalidade Acesso Aberto sob a licença Creative Commons Atribuição 4.0 (CC-BY 4.0), a qual permite uso irrestrito, distribuição, reprodução em qualquer meio, desde que o autor e a fonte sejam devidamente creditados. 